\title{
3D CFD Analysis of an Abnormally Rapid Combustion Phenomenon in Downsized Gasoline Engines
}

\author{
B. Réveillé and A. Duparchy \\ Institut français du pétrole, IFP, Direction Techniques d'Applications énergétiques, 1-4 avenue de Bois Préau, \\ 92852 Rueil-Malmaison Cedex - France \\ e-mail: benjamin.reveille@ifp.fr - alexandre.duparchy@ifp.fr
}

\begin{abstract}
Résumé - Analyse par MFN 3D d'un phénomène de combustion anormalement rapide sur moteurs essence éco-suralimentés - L'explosion du prix du pétrole et une conscience environnementale accrue entretiennent la course vers les GMP (Groupe Moto Propulseur) sobres. Même si les hybrides sont la solution la plus médiatisée, il y a encore beaucoup de travail à faire sur les systèmes de combustion. L'éco-suralimentation poussée des moteurs essence est très prometteuse et l'IFP propose un concept novateur dans ce domaine. Cependant, l'augmentation des puissances spécifiques s'accompagne de contraintes et défis supplémentaires. De nombreux phénomènes de combustion ont été rencontrés allant du simple cliquetis au rumble et doivent être compris et maîtrisés afin d'optimiser le système de combustion. Une combustion anormalement rapide, mais non destructive et semble-t-il stable, en fait partie. Les outils de MFN (Mécanique des Fluides Numérique) 3D ont été mis à contribution afin d'analyser et comprendre ce qui se cache derrière ce phénomène particulier de combustion.
\end{abstract}

\begin{abstract}
D CFD Analysis of an Abnormally Rapid Combustion Phenomenon in Downsized Gasoline Engines - Soaring oil prices combined with increased environmental awareness maintain the drive for fuel-efficient and $\mathrm{CO}_{2}$-friendly powertrains. Even if hybrids seem to be the media friendly solution, there is still much work to be done on combustion systems. For gasoline engines aggressive downsizing seems promising and IFP proposes an innovative approach. However, new difficulties arise as specific power outputs are increased. Various combustion phenomena are encountered from simple knock to rumble and must be understood and mastered in order to fully optimize the combustion system. Abnormally rapid yet non destructive and seemingly stable combustion is one of these new phenomena. $3 D$ CFD (Computational Fluid Dynamics) simulation tools were used in order to investigate and understand what lies behind this particular combustion.
\end{abstract}




\section{ACRONYMS}

AKTIM Arc \& Kernel Tracking Ignition Model

$\begin{array}{ll}\text { ALE } & \text { Arbitrary Lagrangian Eulerian } \\ \text { aTDC } & \text { after Top Dead Center } \\ \text { BDC } & \text { Bottom Dead Center } \\ \text { BMEP } & \text { Break Mean Effective Pressure } \\ \text { CAD } & \text { Crank Angle Degree } \\ \text { CFD } & \text { Computational Fluid Dynamics } \\ \text { ECFM } & \text { Extended Coherent Flame Mode }\end{array}$

ECFM3Z 3-Zone Extended Coherent Flame Model

EGR Exhaust Gas Recirculation

FAER Fuel Air Equivalence Ratio

IMEP Indicated Mean Effective Pressure

OEM Original Equipment Manufacturer

RNG Re-Normalization Group

RPM Revolution/Rounds Per Minute

SMP Shared Memory Parallel

TDC Top Dead Center

TKI Tabulated Kinetics of Ignition

\section{INTRODUCTION}

In a period of increased environmental awareness - stimulated by global warming - and soaring oil prices as demand reaches record levels with that of developing countries, much strain is put on powertrains. As concerned regulators and clients push for more efficient and $\mathrm{CO}_{2}$-friendly vehicles, OEMs introduce new technologies to respond to such a demand. Even if the media coverage has favored hybridization, other solutions, not necessarily incompatible with hybridization exist. Aggressive engine downsizing is one of the technological solutions that IFP is working on. While developing IFP's downsizing concept, abnormally rapid combustions, were identified. They were encountered under low speed and mid to high load operating conditions and for various engines. The paper will show how 3D CFD was used to analyze the phenomenon and identify the peculiar combustion that occurs in such a case.

\section{ABNORMALLY RAPID COMBUSTION IDENTIFICATION AND SIMULATION CONFIGURATION}

\subsection{Abnormally Rapid Combustion Identification}

Aggressive downsizing implies heavy increase of specific power output of engines and therefore higher IMEPs. On the test benches, this has lead to the observation of abnormal combustions ranging from simple knock to full out rumble.
They have been found in various engines for low speed, mid to high load operating conditions. Abnormally rapid yet and non destructive combustions have been identified on low speed and mid to high load operating points. Figure 1 illustrates a typical heat release rate during such a combustion. It starts out seemingly normally and then a rapid burn rate increase can be observed. SOI (Start Of Injection) variations performed on a particular engine showing very little effect, this particular combustion phenomenon seems relatively stable. Heat release increase suggests that some sort of autoignition is involved yet its level and non destructiveness suggest that it is not completely massive auto-ignition, also known as rumble, encountered under low speed and very high load operating conditions.

In order to better identify what lies behind this particular phenomenon the 3D CFD analysis of an operating point was decided upon.

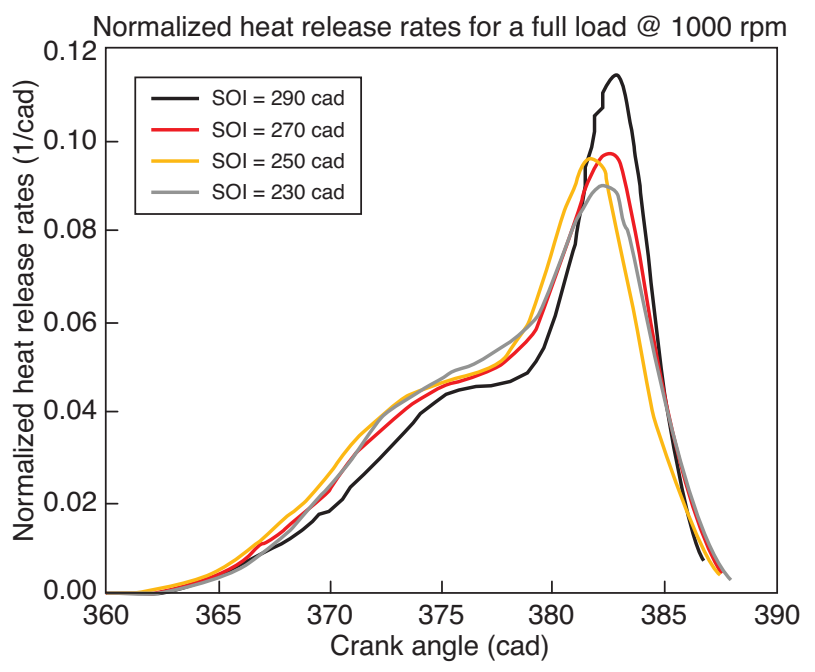

Figure 1

Illustration of an abnormally rapid combustion occurrence with heat release curves on a $1000 \mathrm{rpm}$ mid load operating point.

\subsection{Simulation Configuration}

The configuration chosen for the simulation is an $1.81 \mathrm{I} 4$ Renault F5P engine whose characteristics may be found in Table 1. It is a 4 valve per cylinder engine with a dome in the cylinder head. The injector is mounted on the top of the dome and the spark plug on the side of the dome which allows spray-guided operation as shown in Figure 2. Valve lift profiles are presented in Figure 3 and include an overlap period used to scavenge the hot burnt gases to limit knock occurrence. 
TABLE 1

Geometric characteristics of the combustion chamber

\begin{tabular}{l|c}
\hline Bore & $82.7 \mathrm{~mm}$ \\
Stoke & $83 \mathrm{~mm}$ \\
Connecting rod length & $149.5 \mathrm{~mm}$ \\
Number of cylinders & 4 \\
Total displacement & $1800 \mathrm{~cm}^{3}$ \\
Compression ratio & $10.5: 1$ \\
\hline
\end{tabular}

TABLE 2

Operating point considered

\begin{tabular}{l|c}
\hline Engine speed (rpm) & 1000 \\
Spark advance (cad) & 0 \\
IMEP / BMEP (bar) & $13.54 / 12.25$ \\
FAER (-) & 1.0 \\
\hline
\end{tabular}

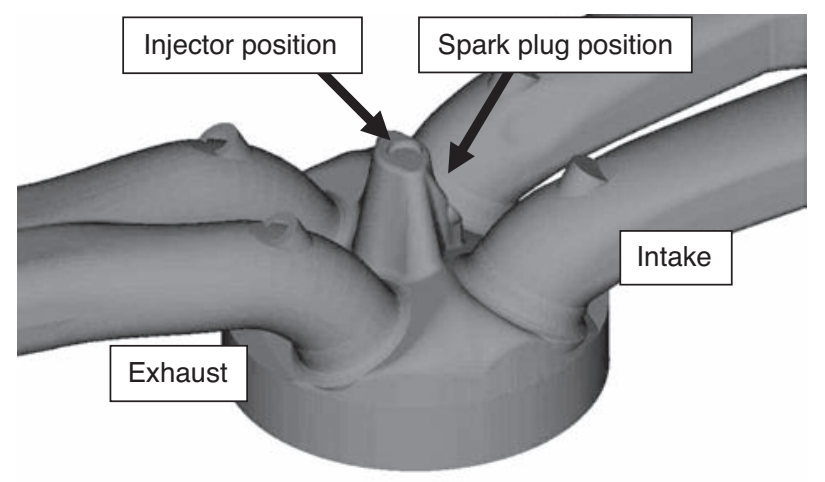

Figure 2

View of the cylinder head with dome, injector and spark plug positions.

The particular operating point considered on the engine is a 12 bar BMEP at $1000 \mathrm{rpm}$. All operating conditions can be found in Table 2. As stated earlier this is a low speed mid load operating point. The rapid combustion occurrence is visible on the experimental mean pressure and heat release curves found in Figure 4. A very steep pressure rise accompanied by a peak in the heat release is visible for all cylinders. One can notice that the behaviors of the various cylinders are quite different especially when looking at the heat release rate.

\section{3D CFD TOOLS}

In this section, the 3D CFD tools used in the study in order to reproduce and analyze the rapid combustion phenomenon observed on the selected configuration are described.

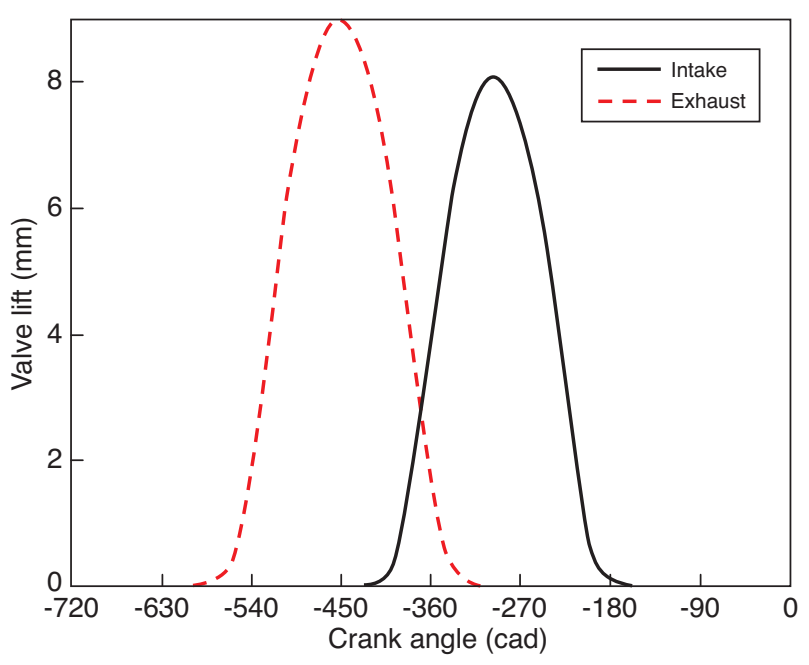

Figure 3

Valve lift profiles with overlap.

\subsection{IFP-C3D Code}

The IFP-C3D code is a parallel hexahedral unstructured code developed at IFP [1,2]. The Navier-Stokes equations are solved using a finite volume method extended with the ALE method. The code uses the well-known time splitting decomposition. The temporal integration scheme is largely implicit. Concerning the liquid phase, evaporation and break-up using the Wave-FIPA model and spray - wall interaction are included. For turbulent combustion, the ECFM3Z model developed at IFP is used [12]. Species (and tracers), energy and the RNG k- $\varepsilon$ turbulent diffusion terms are implicitly solved by a generic diffusion routine. Moreover, efficiently preconditioning the pressure matrix drastically reduces the simulation time. The convection terms are explicitly subcycled. A second order upwind scheme for scalar and momentum convection is used. The OpenMP paradigm is used for parallelization, as it is standardized, portable, scalable and adapted to modern super-scalar SMP machines. Overall, about $50 \%$ of the code is parallelized providing a very good and scalable speed-up (around 3 for 4 processors). Details and extensive validations of the code may be found in [3].

\subsection{Physical Models}

In this section we describe the two most important physical models, for auto-ignition and combustion, that will be used for the simulation.

\subsubsection{TKI Auto-Ignition Model}

To numerically study this particular combustion phenomenon, an auto-ignition model is needed which has to provide the autoignition delay and an accurate description of the subsequent 

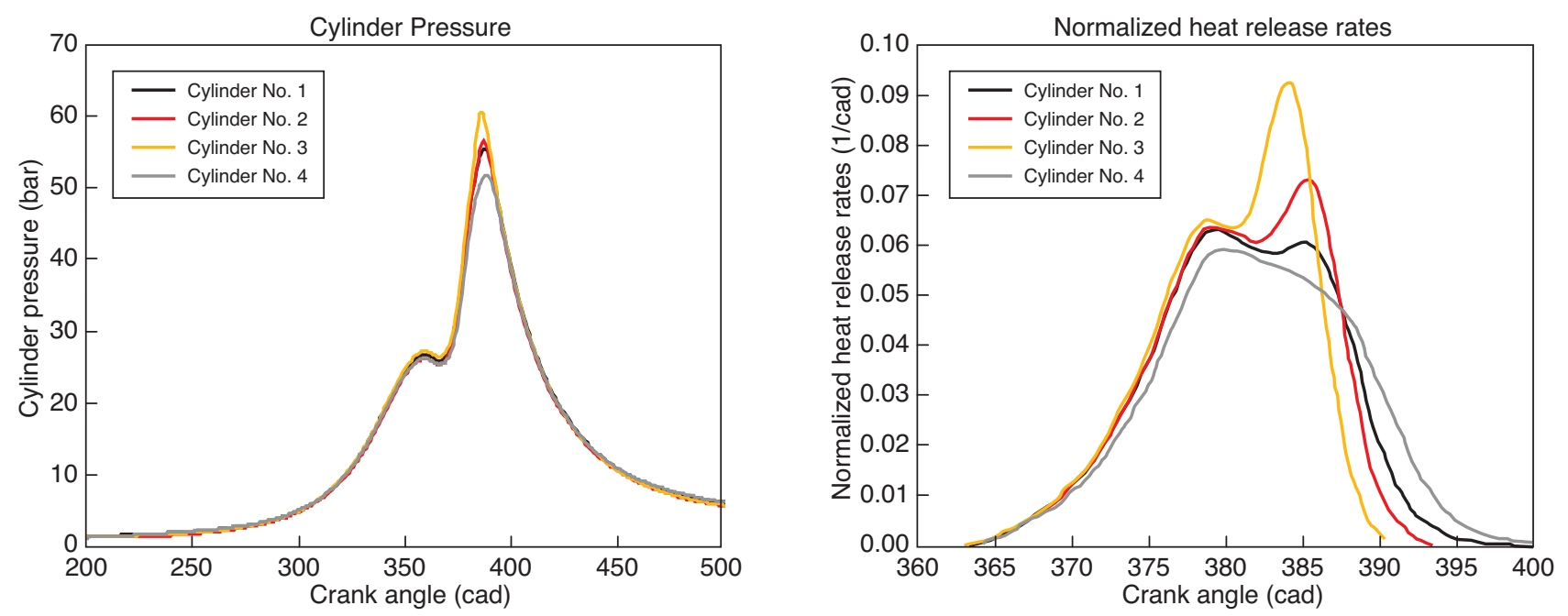

Figure 4

Pressure traces and heat releases for the selected configuration.

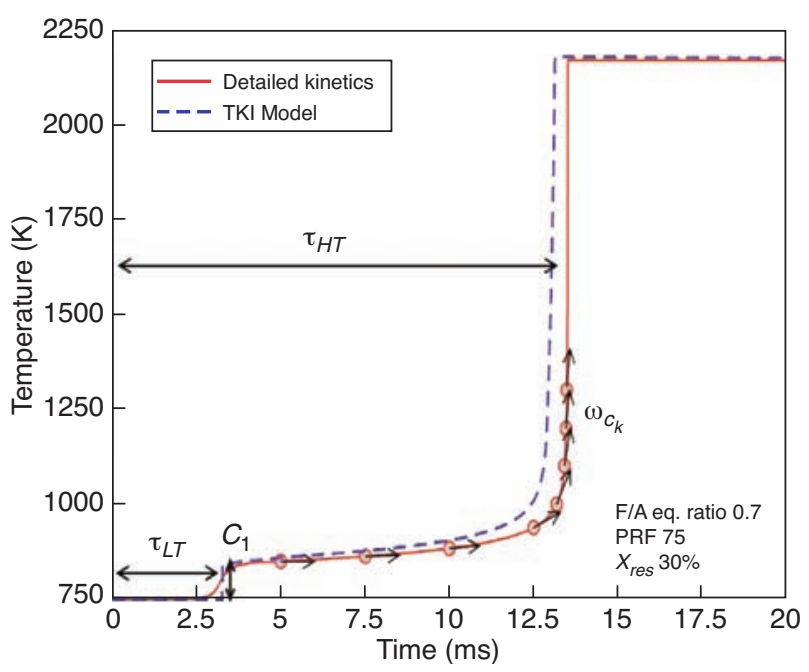

Figure 5

Temperature profiles obtained with the model and complex chemistry calculation code (solid line).

chemistry reactions. Indeed, a precise knowledge of the reaction rates is needed to correctly predict the pressure rise during combustion. The latest version of the TKI autoignition model [14] meets all these requirements. It relies on tabulated auto-ignition variables deduced from detailed chemistry calculations performed with the Senkin code, which is part of the Chemkin package $[8,9]$. The detailed mechanism has been generated by the Département de Chimie Physique des Réactions (Nancy, CNRS) for mixtures of $n$-heptane and iso-octane [10]. This mechanism contains 1992 reactions between 416 species. The 3D model variables are calculated once and for all for 68400 different initial thermodynamic conditions and are stored in look-up tables. The fresh (or unburnt) gas quantities that are used as input parameters of the auto-ignition lookup tables are temperature, pressure, Fuel/Air equivalence ratio, rate of dilution and the octane number. Figure 5 shows an example of the temperature profile predicted by the TKI model and a comparison with the temperature profile computed with the detailed chemistry mechanisms. In this example, the thermodynamic conditions lead to a first part of the combustion controlled by the cool flame. To represent this phenomenon, two auto-ignition variables are defined: the auto-ignition delay $\tau$ and the portion $C_{1}$ of fuel consumed by the cool flame. Then, main ignition is modeled based on reaction rates $\omega_{c k}$ tabulated as a function of the progress variable. When the thermodynamic conditions lead to the absence of the cool flame effect, $C_{1}$ is simply zero and the combustion is entirely described with reaction rates.

As in an internal combustion engine thermodynamic conditions evolve with the piston motion, all model variables (and among them the delay) extracted from the database vary on a per cell basis. To take this evolution into account, an intermediate species is considered for the in-cell auto-ignition delay whose concentration has a growth rate proportional to the local fuel tracer concentration and to the relevant autoignition delay. The actual auto-ignition occurs when the intermediate species concentration reaches that of the fuel tracer.

\subsubsection{ECFM3Z Combustion Model}

The ECFM3Z has been recently developed at IFP for both SI and Diesel applications. This model is based on the ECFM model [11] devoted to SI combustion, which has been extensively validated [11]. The ECFM3Z model is thoroughly described in [12] therefore only a brief description of this model is given here. 


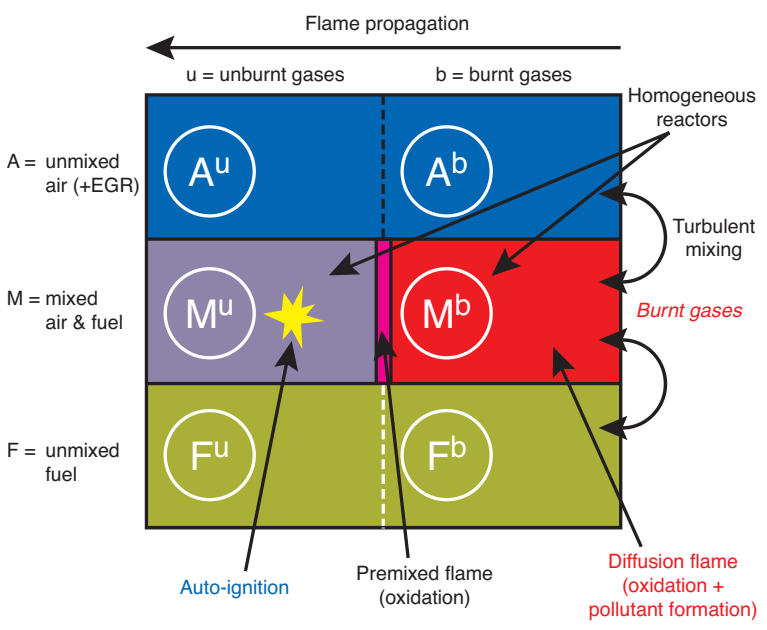

Figure 6

Description of the ECFM3Z combustion model.

Compared to the ECFM model, the ECFM3Z model adds a description of the state of mixing between fuel and air by splitting the computational cell into three mixing zones (cf Fig. 6): region $\mathrm{F}$ contains only pure fuel, region $\mathrm{M}$ contains a mixture of fuel and air and region A contains only air plus possible EGR. During injection, the evaporation of the spray droplets leads to a source term for mass in region $\mathrm{F}$. The fuel in region $\mathrm{F}$ begins to mix with the air+EGR of region $\mathrm{A}$ and forms a mixture in region M. It is assumed that the characteristic mixing time depends on the characteristic time scale of the turbulence:

$$
\tau_{m}=f\left(\frac{k}{\varepsilon}\right)
$$

The air+EGR-fuel can then auto-ignite in region M. When the auto-ignition delay is reached (see above for auto-ignition model description), combustion in region $\mathrm{M}$ starts thereby dividing it into two zones: a fresh and a burnt gas zone (referenced as $\mathrm{M}^{\mathrm{u}}$ and $\mathrm{M}^{\mathrm{b}}$ in Fig. 6). As the fresh gases are oxidized by auto-ignition, the hot products formed are added to region $\mathrm{M}^{\mathrm{b}}$.

The pure fuel and air+EGR of regions $\mathrm{F}$ and A carry on mixing in region $\mathrm{M}$ after the auto-ignition process has begun. In this case, part of this mixture goes into the fresh gas region $\mathrm{M}^{\mathrm{u}}$ and the other in the burnt gas region $\mathrm{M}^{\mathrm{b}}$. In the latter region, we assume that fuel and air burn as in a diffusion flame since the reaction rate is essentially controlled by mixing.

As the oxidation process continues, the formation of pollutants (soot and $\mathrm{NO}_{\mathrm{x}}$ ) is taken into account in region $\mathrm{M}^{\mathrm{b}}$. The $\mathrm{NO}_{\mathrm{x}}$ formation is described by the extended Zeldovich mechanism [13], state of the art model for industrial CFD codes for such applications. As these processes highly depend on the local temperature, equilibrium kinetics are carried out in this region in order to evaluate accurately the burnt gas temperature.
The ECFM3Z model, coupled with the spray model has proven quite effective for the simulation of conventional DI combustion systems, gasoline engines stratified or not [11].

\section{SIMULATION METHODOLOGY}

In this section, we describe the choices made in order to carry out the simulation.

\subsection{Physical Models Used}

In order to carry out the simulation here are the main models chosen:

- k-epsilon rng turbulence model [16],

- Angelberger \& al law of the wall model (modified Kays \& Crawford),

- injection model [17, 19],

- AKTIM spark ignition model [20],

- TKI auto-ignition model [6, 14],

ECFM3Z combustion model [12].

\subsection{Mesh}

The geometry of a cylinder being symmetrical as well as the applied boundary conditions (c.f. Sect. 3.4), the simulations were carried out on half the domain. A view of the mesh can be found in Figure 7 featuring the combustion chamber but also the intake and exhaust ports. There are 3 topological mesh phases during the simulation:

- Exhaust \& scavenging: exhaust \& intake pipes are present as well as the chamber,

- Intake: intake pipe and chamber are present,

- Compression \& combustion: only the chamber is considered.

The number of cells in the mesh for each topological phase can be found in Table 3 .

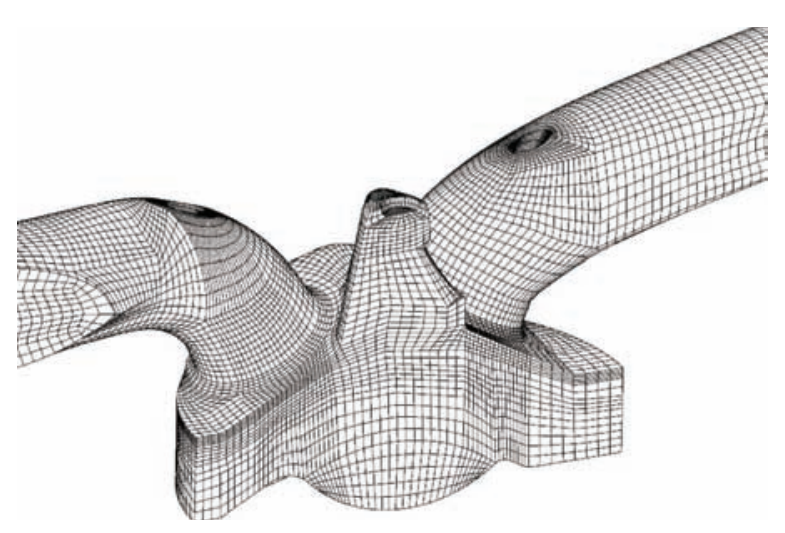

Figure 7

View of the half chamber mesh. 
TABLE 3

Number of cells in the meshes

\begin{tabular}{|c|c|c|}
\hline Computation phase & \multicolumn{2}{|c|}{ Number of cells } \\
\hline Exhaust \& scavenging & \multicolumn{2}{|c|}{59989} \\
\hline Intake & 57885 (TDC) & 226619 (BDC) \\
\hline Compression \& combustion & 57672 (TDC) & 161016 (BDC) \\
\hline
\end{tabular}

\subsection{Initial Conditions}

The simulation starts at -405 cad which corresponds to the opening of the intake valve. At that instant, the exhaust valves are still open as can be seen in Figure 3. The mesh is separated into three zones: intake, chamber and exhaust which are all initialized with constant pressures and temperatures as found in Table 4. Fresh air is found in the intake port while burnt gases can be found in the chamber and exhaust port.

\section{TABLE 4}

Initial conditions in the computational domain

\begin{tabular}{l|c|c|c}
\hline & Chamber & Exhaust & Intake \\
\hline Pressure (bar) & 0.615 & 1.1335 & 1.2361 \\
Temperature (K) & 686.15 & 686.15 & 322.15
\end{tabular}

\subsection{Boundary Conditions}

Specific boundary conditions are applied to the inlet, outlet and walls.

\subsubsection{Inlet/Outlet}

Time dependent pressures (c.f. Fig. 8) are imposed at the inlet and outlet. These are experimental pressures acquired on the test bench.

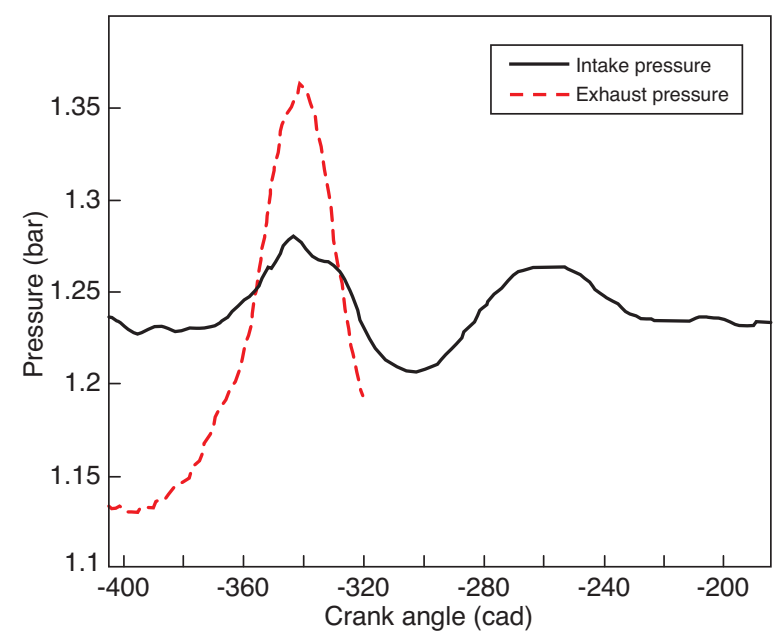

Figure 8

Imposed inlet and outlet pressures.

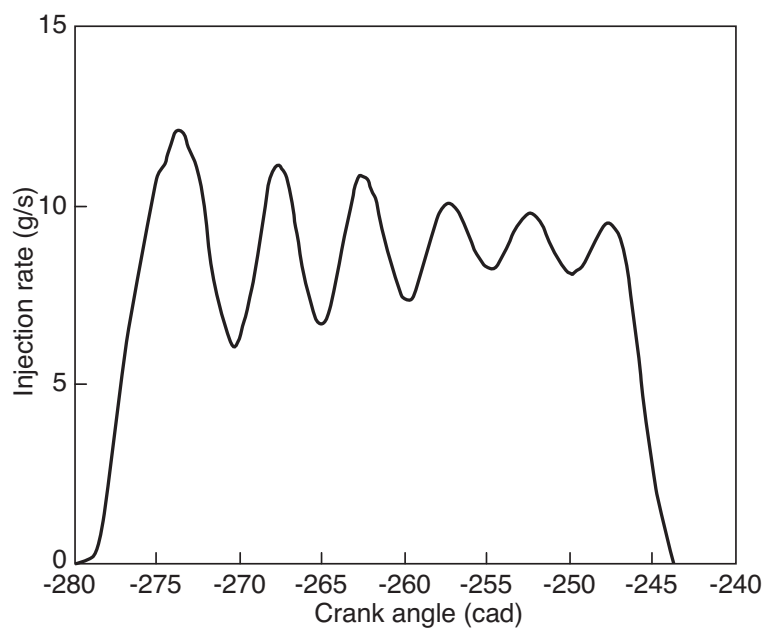

Figure 9

Injection rate.

\subsubsection{Walls}

Constant temperatures are applied to the walls, however different wall types have different temperatures as shown in Table 5.

TABLE 5

Imposed wall temperatures

\begin{tabular}{c|c|c|c|c}
\hline Piston & Cylinder head & Cylinder liner & Intake valve & Exhaust valve \\
\hline $500 \mathrm{~K}$ & $450 \mathrm{~K}$ & $420 \mathrm{~K}$ & $420 \mathrm{~K}$ & $420 \mathrm{~K}$ \\
\hline
\end{tabular}

\subsection{Injection}

The injection rate used in the simulation is rebuilt from experimental measurements of a similar injection using the same injector and can be found in Figure 9. Detailed injection information is presented in Table 6 .

TABLE 6

Injection charateristics

\begin{tabular}{l|c} 
Injector position & central \\
Start of injection (cad) & -280 \\
End of injection (cad) & 36.27 \\
Injection pressure (bar) & 50.5 \\
Injected quantity (mg) & 43.16
\end{tabular}

\section{RESULTS}

The simulation was done in two phases, the gas exchanges and the combustion. The first phase aims at obtaining realistic mixture preparation and aerodynamics in the combustion chamber before moving on to the compression and combustion. Fitting 




a)

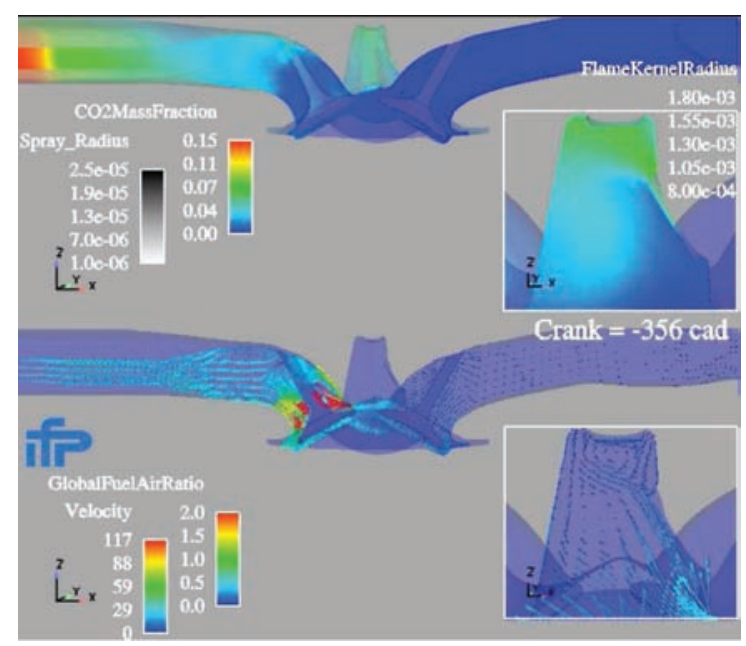

c)

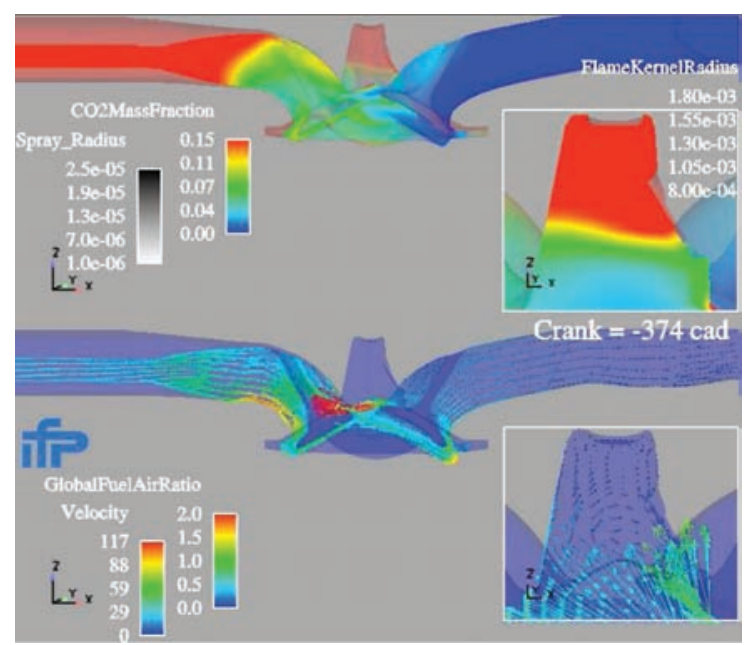

b)

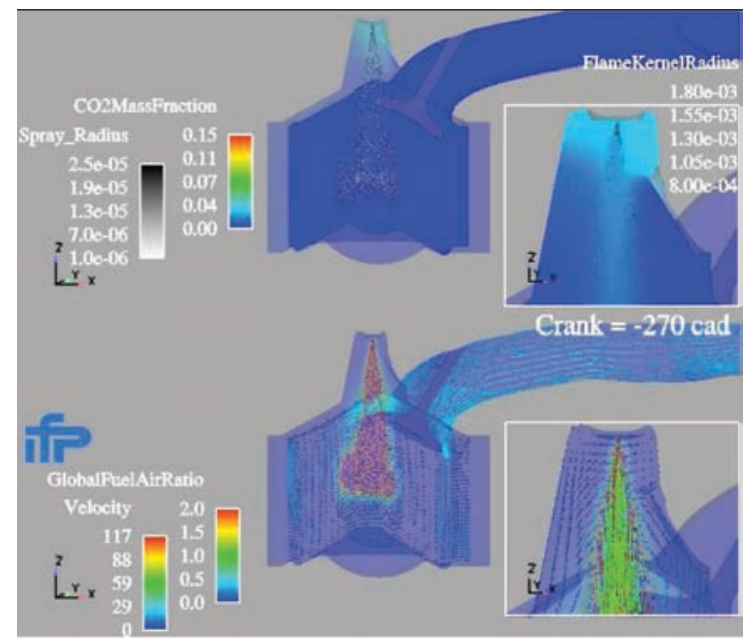

d)

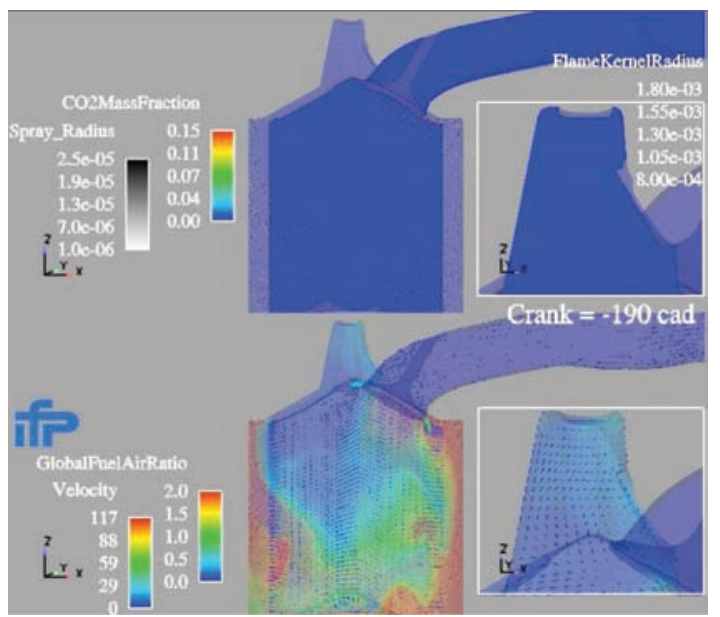

e)

Figure 10

Exhaust, intake and scavenging visualization. 
of gas exchange data was done between the two in order to ensure that the correct masses of fuel and air are trapped in the cylinder before compression and combustion.

\subsection{Exhaust, Scavenging and Intake}

Figure 10 shows the evolution of several fields during the exhaust, scavenging and intake. Each image is composed of 2 views:

- Top: $\mathrm{CO}_{2}$ mass fraction field which represents the separation between fresh and burnt gases and helps identify the quality of the scavenging, red being burnt gases and blue fresh intake air.

- Bottom: Velocity vector (colored by velocity) and FAER field which shows the mixture formation.

In each image there is a global view of the exhaust pipe, combustion chamber, and intake pipe and a zoomed view of the cylinder head dome.

For such an operating point, which may be knock sensitive due to low engine speed and load, it is necessary to eliminate all hot burnt gases. The images from Figure 10 illustrate the fact that the scavenging is efficient. Indeed, only $0.5 \%$ of burnt gases are present in the chamber at the end of the intake stroke and although there is some short-circuiting of the fresh intake gases, it is quite limited as seen at -356 cad. At -356 cad some hot burnt gases still remain in the cylinder dome, however the injection and gas entrainment that it generates, as can be seen in the dome zoom at -270 cad in Figure 10, flush the burnt gases out of the cylinder head dome and into the bulk of the chamber where the dilution by fresh gases renders them unnoticeable.

At intake valve closure, -190 cad, the injection is over and the fuel is mostly located near the piston and the cylinder liner.

\subsection{Compression and Combustion}

Before computing the compression and combustion phases, the intake pressure is fitted (adjusted from 1.21 bar to 1.28 bar) to the experimental value to ensure that the thermodynamic conditions in the combustion chamber are as close as possible to their experimental counterparts. Some uncertainties remain such as the mass of air that was short-circuited or the rate of residual burnt gases which may have an influence on the combustion.

\subsubsection{Compression and Fuel Distribution Homogenization}

During compression, pressure and temperature increases help vaporize the remaining spray droplets, while the tumble motion (represented by the arrows in Fig. 11) leads to a partial homogenization of the fuel to air equivalence ratio in the bulk of the combustion chamber. A richer zone remains in the squish region below the intake valves, the leanest region being in the cylinder head dome near the injector nozzle and in the piston bowl.

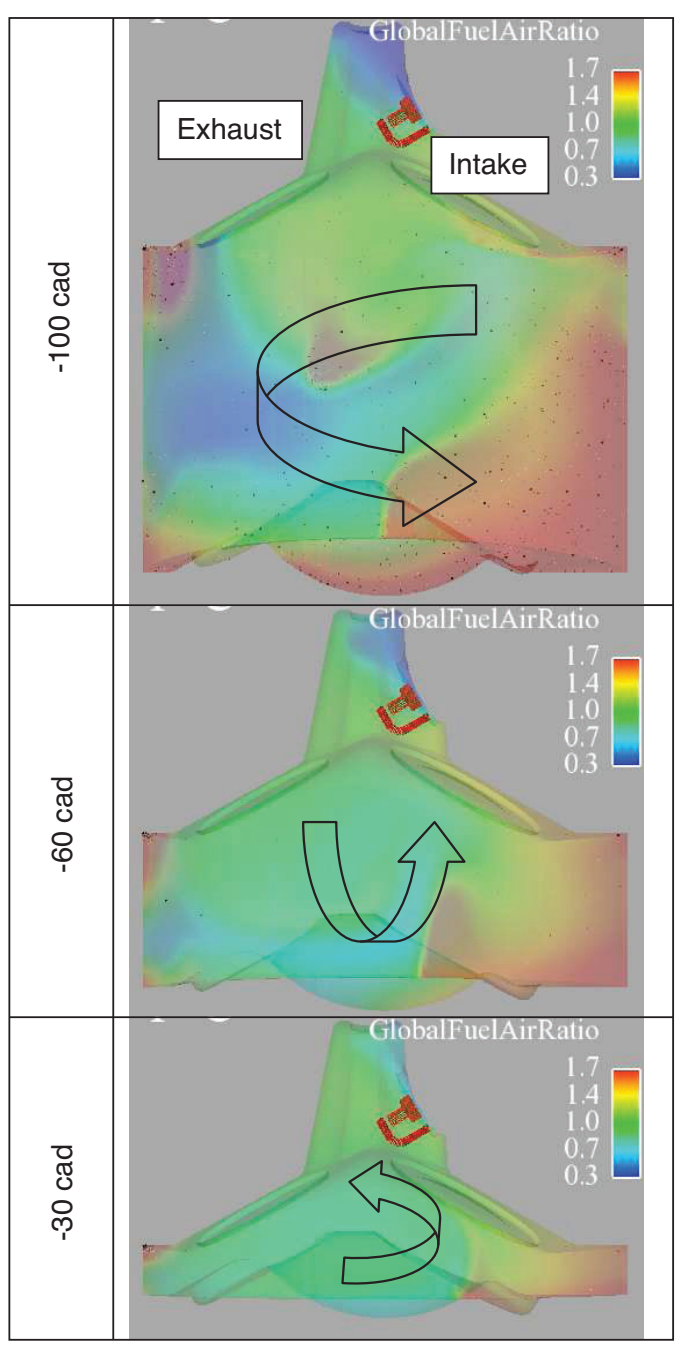

Figure 11

Homogenization during compression.

\subsubsection{Combustion}

Five combustion calculations were performed. The various pressure traces can be found in Figure 12.

The baseline case does not start combustion fast enough as can be seen in Figure 12. Comparing pressure traces for cases $\mathrm{A}, \mathrm{D}$ and $\mathrm{E}$ shows that auto-ignition plays an important part in the combustion as without the relevant model the pressure trace is quite different. Likewise when the spark ignition model is deactivated we see that there is an auto-ignition that occurs but much later in the cycle. So before looking at 3D CFD fields we can say that the simulated baseline case ignites with the spark plug and then auto-ignition occurs. This is not the case of the experimental pressure trace where auto-ignition probably occurs before spark ignition since the pressure rise starts before ignition. 


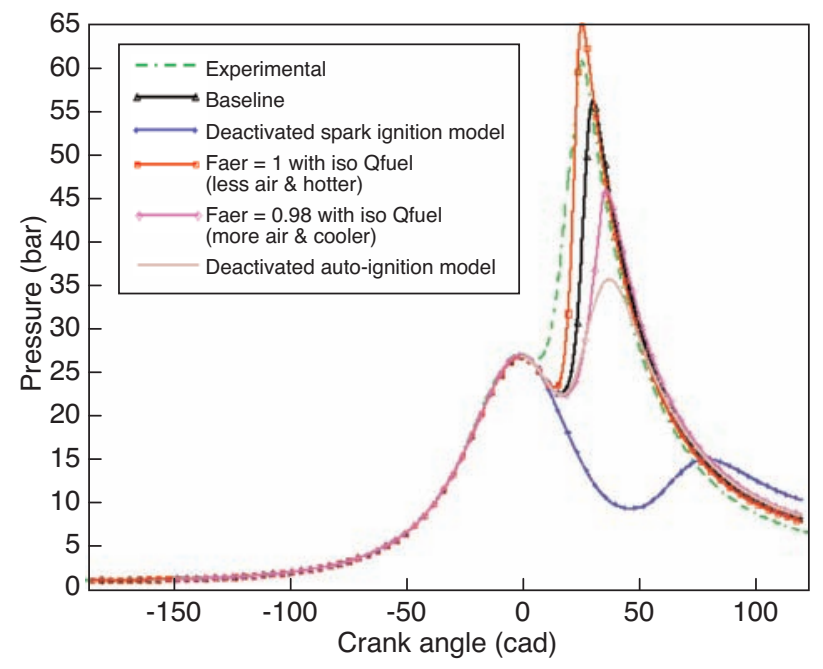

Figure 12

Pressure traces for various combustion calculations.

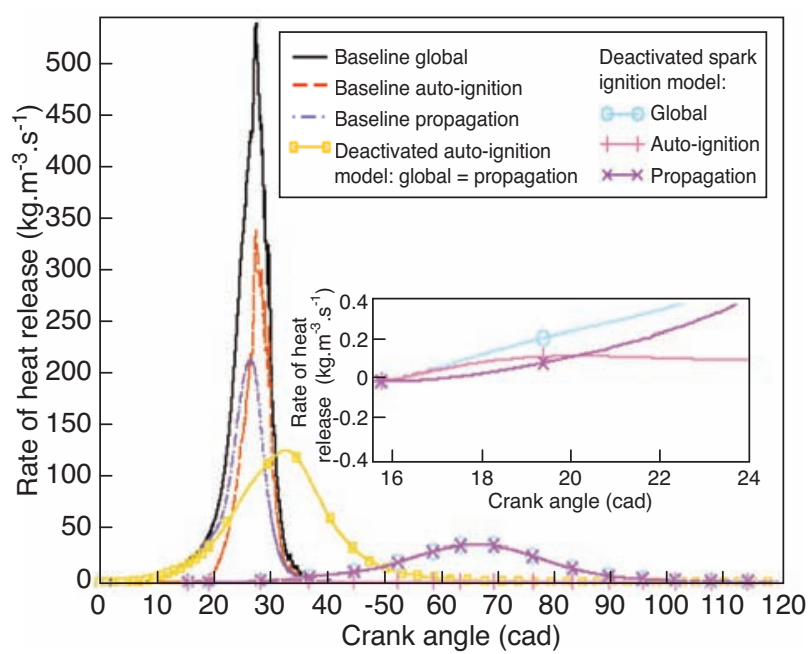

Figure 13

Heat release analysis for various combustion calculations.
Since the simulated start of combustion seems late on the baseline case and that auto-ignition comes in after spark ignition, two extra simulations cases (B and C) were performed.

TABLE 7

Computed combustion cases

\begin{tabular}{c|l}
\hline Case & \multicolumn{1}{|c}{ Description } \\
\hline A & Baseline \\
B & Increased fuel to air equivalence ratio (faer $=1.00)$ \\
C & Decreased fuel to air equivalence ratio $($ faer $=0.98)$ \\
D & Deactivated auto-ignition model \\
E & Deactivated spark ignition model \\
\hline
\end{tabular}

TABLE 8

Temperatures at BDC and TDC + First auto-ignition crank angle

\begin{tabular}{l|c|c|c}
\hline Case & A & B & C \\
\hline Temperature at BDC & $349 \mathrm{~K}$ & $351.5 \mathrm{~K}$ & $344.7 \mathrm{~K}$ \\
Temperature at TDC & $720 \mathrm{~K}$ & $723 \mathrm{~K}$ & $715.2 \mathrm{~K}$ \\
Auto-ignition angle & $14.3 \mathrm{cad}$ & $10.7 \mathrm{cad}$ & $23.4 \mathrm{cad}$ \\
\hline
\end{tabular}

Fuel to air equivalence ratio increase and decrease were performed by varying just the intake air mass (decrease and increase, respectively). It has a double effect by also decreasing and increasing the in-cylinder temperature at intake valve closure (since volume and pressure are unchanged). This variation was meant to assess the influence of temperature on the auto-ignition delay plus evaluate the impact of the unknown experimental short-circuiting. Table 8 contains the crank angles at which the first auto-ignition occurs for cases A through C. We can see in this table as in Figure 12 that auto ignition occurs sooner with the slightly higher intake temperature and that the auto-ignition occurrence appears very sensitive to temperature or fuel to air equivalence ratio. This suggests that auto-ignition delay (which seems too long) could potentially be improved either with a greater BDC temperature or with an even more advanced auto-ignition model.

Figure 13 gives a more in-depth analysis of the combustion occurrence by comparing heat release due to auto-ignition and flame propagation for case A, D and E.

For case A we see that initially flame propagation, emanating from spark ignition since no previous auto-ignition heat release has occurred, is the only form of combustion but is later (around $25 \mathrm{cad}$ ) caught up and surpassed by auto-ignition. The resulting combustion is rather quick with auto-ignition occurring during $30 \mathrm{cad}$ which is about the same duration as that of flame propagation, while producing more than half the heat release. When deactivating the auto-ignition model, only flame propagation is found, the resulting combustion is slower (55 cad width). Finally when the spark ignition model is deactivated we see (in the zoom) that a small initial ignition occurs through auto-ignition around $16 \mathrm{cad}$, initiating flame propagation which surpasses it around $20 \mathrm{cad}$.

This analysis has helped grasp the global behaviour of the combustion taking place, the next step is an in depth look at the $3 \mathrm{D}$ fields to understand where auto-ignition and propagation occur. Figure 14 shows temperature and fuel to air equivalence ratio fields while superposing auto-ignition fuel consumption and flame propagation iso-surfaces as found while processing $3 \mathrm{D}$ results for case $\mathrm{B}$.

Combustion takes place in two phases after initial spark ignition at 2 cad aTDC:

- Only propagation from 2 to 12 cad aTDC. AKTIM model [20] flame kernels are clearly visible during spark ignition 

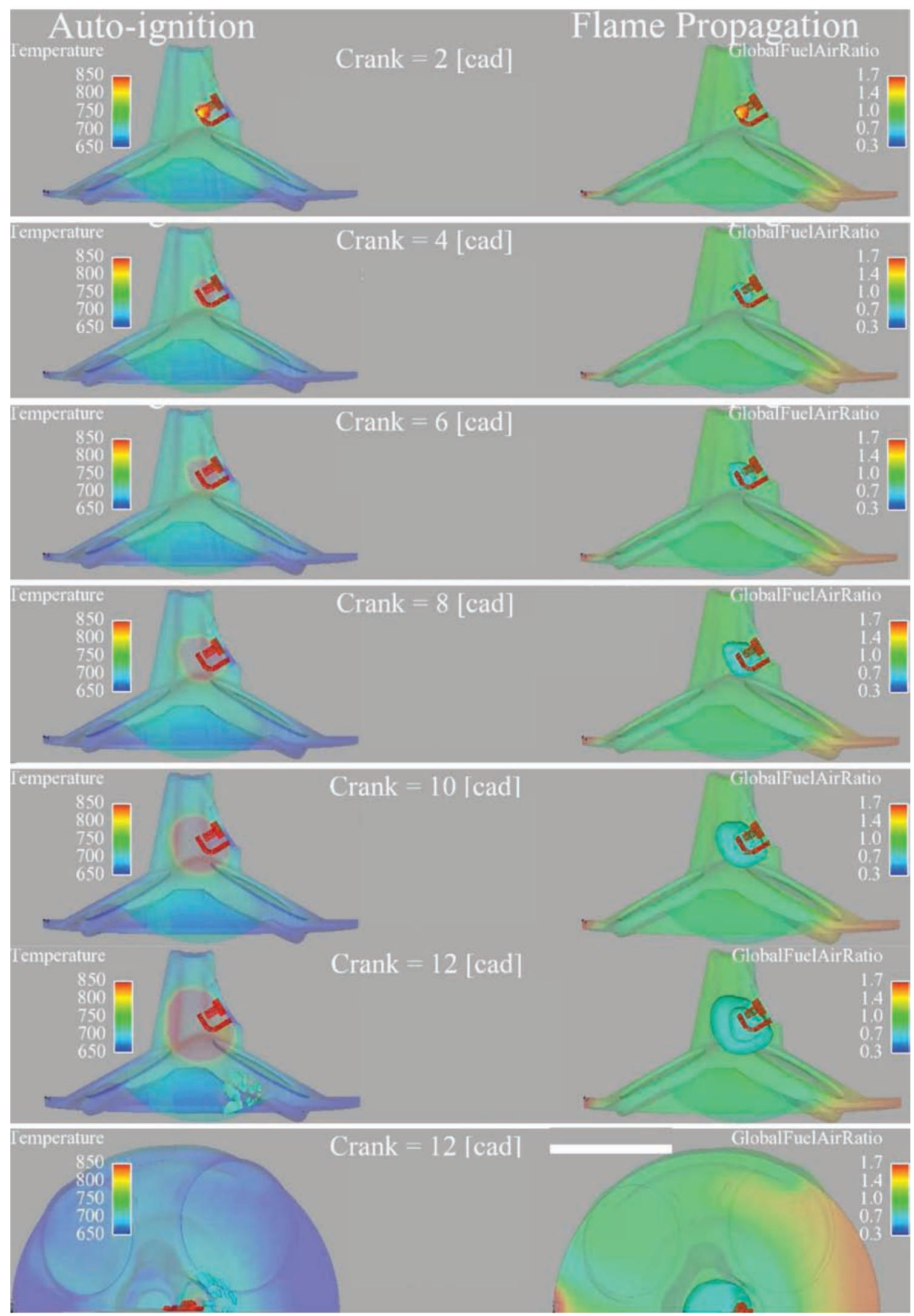

Figure 14a 

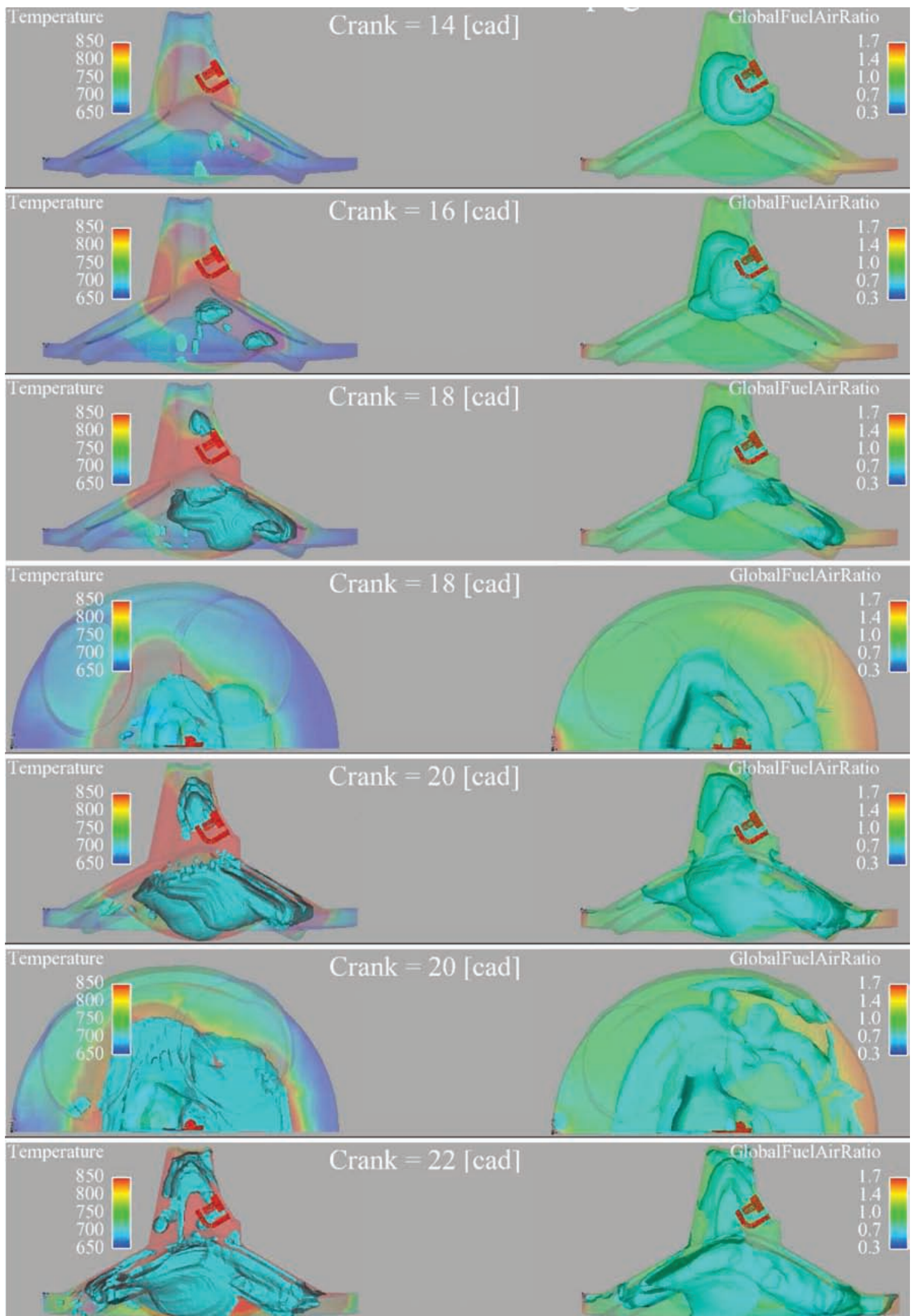

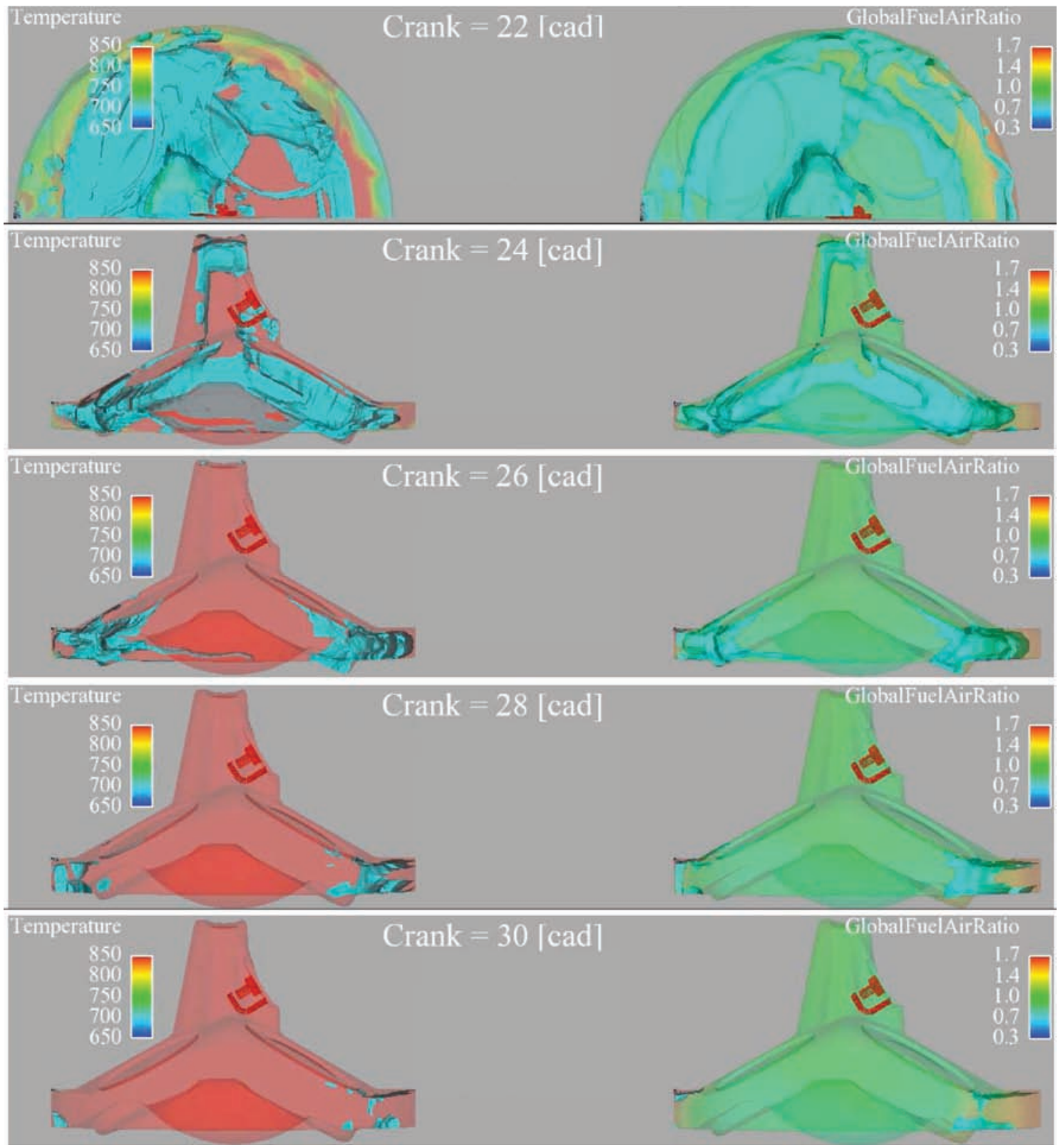

Figure 14c

Analysis of the location of auto-ignition and flame propagation given temperature and fuel to air equivalence ratio fields for various crank angles. On the left the temperature field and auto-ignition iso-surface are found, while on the right the fuel to air equivalence ratio field and flame propagation iso-surface are found.

at 2 cad aTDC. Then flame surface is deposited and starts to propagate as visible $4 \mathrm{cad}$ aTDC. At the same time Temperature increases where combustion has occurred clearly differentiating fresh and burnt gas zones.

- Auto-ignition and flame propagation interwoven after 12 cad aTDC. While the initial flame front is still propagating, the first auto-ignition sites appear $12 \mathrm{cad}$ aTDC on the intake side (right side) of the piston valve recesses where fuel to air equivalence ratio is higher than average and tempera- ture is still relatively high, the combination of both inducing a short auto-ignition delay. Thereafter propagation of the initial flame front still occurs and new auto-ignition sites appear in the center of the chamber near the piston. The auto-ignition seems to propagate due to the heat diffusion from hot burnt gases of previous auto-ignitions. 16 cad aTDC flame propagation and auto-ignition site are in contact. By 18 cad bTDC we see a new flame front which has developed, from a massive auto ignition, in the squish 
region on the intake side and will thereafter propagate. From then on auto-ignition and flame propagation are interwoven and in permanent contact as they both create/initiate and destroy each other. Layers of autoignition and flame propagation can then be found progressing throughout the combustion chamber.

Although the combustion has not been perfectly reproduced since the simulated pressure curve does not exactly fit the experimental one, the authors believe that the mixed combustion mode with auto-ignition and flame propagation interwoven identified in the simulation is correct.

The main differences between the experimental combustion and the simulated one are:

- overestimated simulated auto-ignition delay,

- steeper simulated combustion rate of heat release.

These differences could be respectively explained by:

- the auto ignition model still overestimates the ignition delay and can be improved,

- the real mixture presents more heterogeneities which could lead to a slower auto-ignition propagation throughout the combustion chamber.

The auto ignition in this particular simulation seems to burn more than half the fuel in the combustion chamber. So it is getting close to a massive auto-ignition, yet is not there since the thermodynamic and mixture conditions inside the cylinder are sufficient to lead to the progressive/propagating auto-ignition mixed with flame propagation. One could imagine that with load increase, greater thermodynamic constraints could lead to a quicker and more massive auto-ignition, i.e. rumble.

\section{CONCLUSION}

This paper has focused on a particular abnormally rapid, yet non destructive and seemingly stable combustion phenomena which has been identified on low speed mid to high load operating points when performing aggressive downsizings on various engines. A particular engine and operating point on which it occurs were selected and a 3D CFD simulation set up. Although not perfect, as the physics involved are complicated to model, the simulation provides insight into the mixed combustion that takes place. Indeed it appears to be a combustion in which auto-ignition and flame propagation are interwoven as they create/initiate and destroy each other in a layered combustion which propagates throughout the combustion chamber.

When noticing how auto-ignition takes up more than half the combustion, it is possible to imagine that with load increase, in-cylinder thermodynamic conditions become more extreme, and auto-ignition could come sooner in the cycle leading to what is identified as rumble on very high load operating points.

\section{REFERENCES}

1 Zolver M., Torres A., Klahr D. (2001) CFD and Combustion in Engines with an Unstructured Parallel Solver Based on KIVA. Article (1-14), The Fifth International Symposium on Diagnostics and Modeling of Combustion in Internal Combustion Engines, COMODIA 2001, July 2001, Nagoya, Japan.

2 Zolver M., Torres A., Klahr D. (2002) An Unstructured Parallel Solver for Engine Intake and Combustion Stroke Simulation, SAE paper 2002-01-1120.

3 Zolver M., Klahr D., Bohbot J., Laget O., Torres A. (2003) Reactive CFD in Engines with a New Unstructured Parallel Solver, Oil Gas Sci. Technol. 58, 1, 33-46.

4 Zolver M., Bohbot J., Klahr D., Torres A. (2003) An Unstructured Parallel Solver for Multi-phase and Reactive Flows in Internal Combustion Engines, Parallel CFD 2003, Mai 2003, Moscow.

5 http://www.Imsintl.com/imagine, LMS.

6 Colin O., Pires da Cruz A., Jay S. (2005) Detailed chemistry based auto-ignition model including low temperature phenomena applied to 3D engine calculations, Proc. Combust. Inst. 30, 2, 2649-2656.

7 Jay S., Colin O. (2005) Fuel composition influence on autoignition in engine 3D simulations, 20th ICDERS, Montréal, 2005.

8 Lutz A., Kee R., Miller J. (1987) Senkin: A Fortran program for predicting homogeneous gas phase chemical kinetics with sensitivity analysis, Report No. SAND87-8248. UC-4, Sandia National Laboratories.

9 Kee R.J., Rupley F.M., Miller J.A. (1989) Chemkin-II: A Fortran chemical kinetics package for the analysis of gasphase chemical kinetics, Report No. SAND89-8009. UC401, Sandia National Laboratories.

10 Buda F., Bounaceur R., Warth V., Glaude P.A., Fournet R., Battin-Leclerc F. (2005) Progress towards a unified detailed kinetic model for the autoignition of alkanes from $C_{4}$ to $C_{10}$ between 600 and $1200 \mathrm{~K}$, Combust. Flame 142, 1-2, 170186.

11 Colin O., Benkenida A., Angelberger C. (2003) 3D Modelling of Mixing, Ignition and Combustion Phenomena in Highly Stratified Gasoline Engine, Oil Gas Sci. Technol. 58, 1 .

12 Colin O., Benkenida A. (2004) The 3-Zones Extended Coherent Flame Model (ECFM3Z) for computing premixed diffusion combustion, Oil Gas Sci.Technol.59, 6.

13 Heywood J.B. (1988) Internal Combustion Engine Fundamentals, McGraw Hill.

14 Knop V., Jay S. (2006) Latest developments in gasoline autoignition modelling applied to an optical $\mathrm{CAI}^{\mathrm{TM}}$ engine, Oil Gas Sci. Technol.61, 121-138.

15 Knop V., Thirouard B., Chérel J. (2008) Influence of the Local Mixture Characteristics on the Combustion Process in a CAI ${ }^{\mathrm{TM}}$ Engine, SAE paper 2008-01-1671.

16 Han Z., Reitz R.D. (1995) Turbulence Modeling of Internal Combustion Engines using RNG k-e Models, Combust. Sci. Technol. 106, 267-295.

17 Habchi C., Verhoeven D., Huynh Huu C., Lambert L., Vanhemelryck J.L., Baritaud T. (1997) Modeling Atomization and Breakup in High Pressure Diesel Sprays, SAE paper 970881. 
18 Amsden A.A., O'Rourke P.J., Butler T.D. (1989) KIVA-II: A computer program for chemically reactive flows with sprays, Los Alamos, LA-11560-M S.

19 Habchi C., Foucart H., Grubert A. (1999) 3D modeling of gasoline direct injection, spray/wall and spray/liquidfilm interaction, IFP-45457 (in french).
20 Duclos J.M., Colin O. (2001) Arc and Kernel Tracking Ignition Model for 3D Spark Ignition Engine Calculations, 5th Int. Symp. on Diagnostics and Modeling of Combustion in Internal Combustion Engines, COMODIA 2001, Nagoya, Japan.

Final manuscript received in December 2008 Published online in April 2009 or distributed for profit or commercial advantage and that copies bear this notice and the full citation on the first page. Copyrights for components of this work owned by others than IFP must be honored. Abstracting with credit is permitted. To copy otherwise, to republish, to post on servers, or to redistribute to lists, requires prior specific permission and/or a fee: Request permission from Documentation, Institut français du pétrole, fax. +33147527078 , or revueogst@ifp.fr. 